\title{
Experimental Research of English Teaching Management Model Based on Personalized Multimedia Technology
}

\author{
Keqin Lu \\ School of English Language, Panzhihua Radio and TV University, Panzhihua, China \\ Email: 361302359@qq.com
}

How to cite this paper: Lu, K.Q. (2020) Experimental Research of English Teaching Management Model Based on Personalized Multimedia Technology. Open Access Library Journal, 7: e6251.

https://doi.org/10.4236/oalib.1106251

Received: March 22, 2020

Accepted: April 7, 2020

Published: April 10, 2020

Copyright () 2020 by author(s) and Open Access Library Inc.

This work is licensed under the Creative Commons Attribution International License (CC BY 4.0).

http://creativecommons.org/licenses/by/4.0/

\section{(c) (i) Open Access}

\begin{abstract}
The further integration of information technology and subject teaching is the megatrends of teaching reform nowadays. With the help of information technology, teachers, learners and teaching environment have been effectively integrated; the enthusiasm of teachers and students in learning has been greatly improved. However, the actual effect of foreign language learning has not been substantially improved. Instead, they have become optional outside the classroom. How to use the existing equipment and resources to build a personalized learning environment acceptable to learners and can improve the results of learning is a problem that our English teachers should consider. In view of the rationality of constructivism and contextual cognitive theory in supporting individualized classroom learning, combining with the above theory, based on MMFU (Multimedia for You), this paper attempts to realize it in classroom learning through the application case analysis of foreign language learning with the method of materialization and humanization.
\end{abstract}

\section{Subject Areas}

Education

\section{Keywords}

Integration, Personalized Learning, English Teaching Model, Multimedia-Assisted Teaching

\section{Introduction}

With the further integration of educational technology and subject teaching, various new teaching ideas and teaching methods have been deeply rooted in 
people's hearts. Both the teaching manager, the educator, and the learner can use an exploration and practice mentality to try to use new technologies and new ideas to promote and improve the effectiveness of teaching. The application of new technologies, especially the application of multimedia and network technology, is under the network environment or the classroom environment. This new stuff has infiltrated the learning of various disciplines; whether it is the frontline teacher or the graduate student of this major, experts are fully involved in the practical application of new technologies and concepts. The integration of information technology and learning has gone through the period from the use of information technology as a school's information literacy curriculum to the use of information technology as a learning tool to the use of information technology to create a learner-centered learning environment. Information technology and classroom integration are an important measure for teaching reform. Through information technology, teachers, learners, and teaching environments can be effectively integrated. Only in a harmonious classroom environment, combined with real and effective teaching processes and learning activities can the students' quality education and personality be fully developed.

In order to improve the teaching effect of the second language and improve the learner's comprehensive language ability, it began early on that people began to brewing computers for language teaching. Later, the United Kingdom began to produce computer-assisted language learning software. This is the initial application of multimedia in foreign language teaching. Recent years, computer technological advances have made new ways of teaching and learning language become possible in China. The Internet and the rise of computer-mediated communication in particular have provided an ideal learning environment for foreign language learning: offering rich authentic language materials, making real-world situational context, providing representations in multiple modalities, facilitating collaborative activity among students and real-life communication, etc. As the availability of computer hardware and software has grown, more and more English teachers have been engaged in or are trying the practice and research of multimedia-assisted teaching. The real application of multimedia-assisted teaching in English learning, however, does not seem to go as practitioners' expectation. Some problems from these classes are preventing many English teachers applying this innovative teaching mode. The reflection of many educators and learners is that the multimedia environment seems to be a form of burden and conflicts with learning [1]. The big reason is that multimedia and resources have become optional things outside the classroom. How to use existing equipment and resources to create a learning environment where learners are the center of learning activities and learners can accept the learning environment is a question that we should consider.

Education should include all the people on an equal footing, regardless of nationality or class. Successful education should satisfy most people's lives and pursuits. However, the objects of teaching are different individuals. Due to different knowledge backgrounds, learning styles and other factors, students usual- 
ly show different interest in learning and adopt different learning methods in the same course. Therefore, an efficient learning system should treat each student as a single individual. The basic requirement of a personalized learning environment is to be able to provide multiple learning paths for the same knowledge point. In this way, it may make it a lifelong and universal education. Personalized learning is our response to the opportunities and challenges of the future. The goal is to make all children and young people able to make significant progress in school and to grow the talents they will need to make a difference in their future lives. From an individual perspective, human development has both commonalities and individualities, both of which are constrained by various social factors. The commonality reflects the social requirements more, and the personality reflects the individual's requirements more. Futurist Toffler believes that the characteristics of industrial society are standardized, and the characteristics of the information society are individualization and diversification. Education should be based on different individuals to provide different education, in order to enable them to fully play their potential capabilities, and strive to achieve the same social and individual requirements.

In view of this, the management mode of English teaching based on the individualized multimedia technology discussed in this paper integrates the materialized and humanized factors of English teaching. Under the background of the integration of information technology and subject teaching, English teaching provides a new teaching structure, which is conducive to better playing the function of Multimedia Assisted Teaching and improving the effect of English teaching.

\section{The Theoretical Foundation of Foreign Language Personalized Learning in Multimedia Environment}

\subsection{Multimedia-Assisted Teaching Related Theory}

Initially, multimedia-assisted teaching was based on Skinner's behavioral learning theory. Later, the development of computer-assisted instruction has made a new leap forward, mainly reflected in the application of constructivist learning theory and the widespread use of multimedia technology and computer networks, which can be seen from Figure 1 .

Constructivism, sometimes called structuralism, was first proposed by Piaget. According to the constructivist point of view, students' learning is not based on the unilateral orientation of the teacher. It is a multi-dimensional interaction between the teacher and the student and the classmate. It depends on the situation created by the teacher in the class or in the collision of the classmates. In the construction of knowledge in his own mind, it is active. Multimedia technology integrates functions such as audio, video, images, animation and text to help students from the meaning of knowledge, help students to assimilate and adapt knowledge, and encourage students to think positively. This is consistent with the constructivist learning concept and it is also a major advantage of multimedia technology in English reading teaching. 


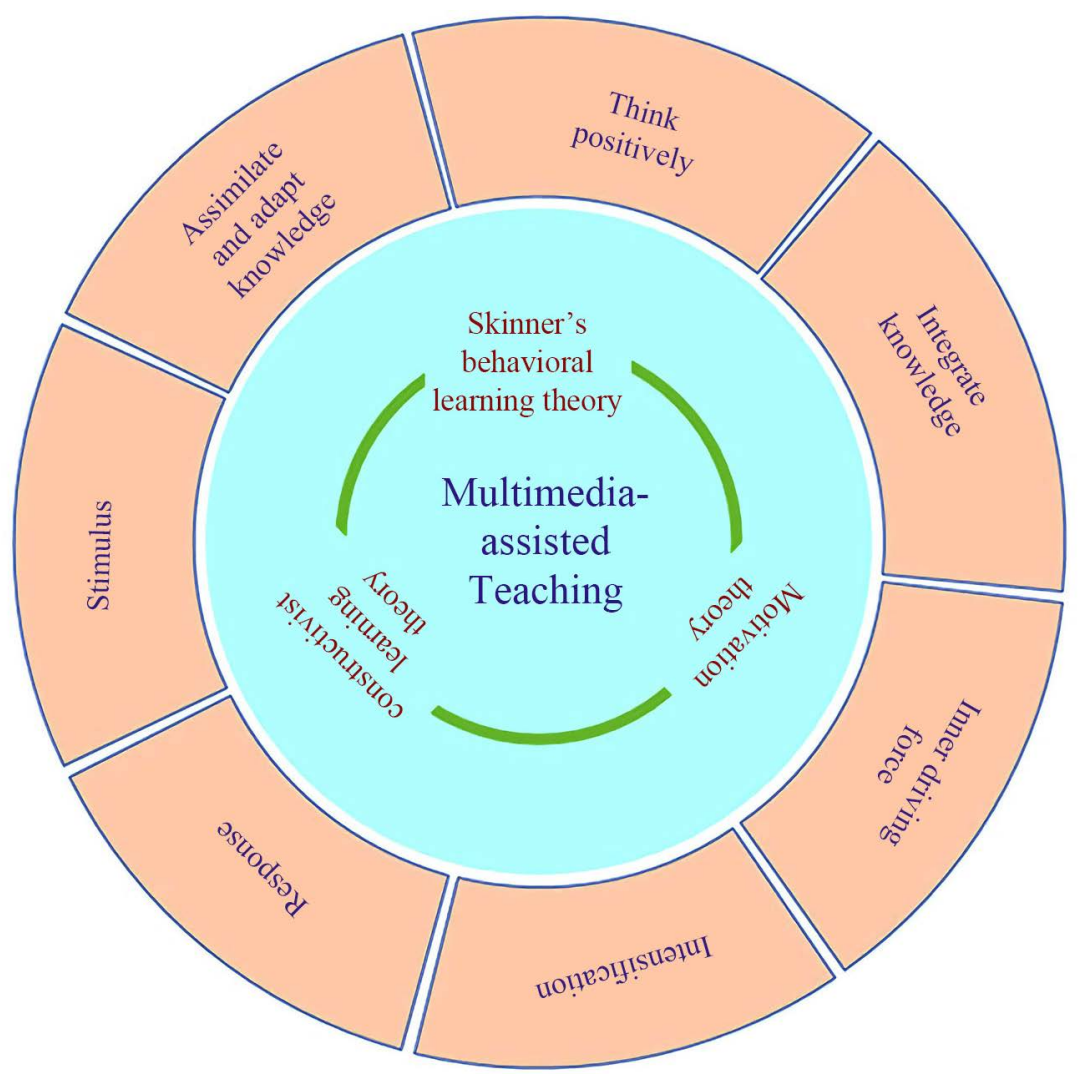

Figure 1. Multimedia environment foreign language teaching theory [2].

Through the above we can easily find that constructivism provides a strong theoretical basis for our multimedia teaching, and multimedia teaching also creates a practical platform for constructivism. The use of multimedia technology is conducive to stimulating students' interests, can promote students to actively explore the unknown, and urges students to continuously integrate knowledge, and constantly improve their meaning on the construction of knowledge. In general, motives for participating in different activities are named after the motives of the activity. Then the motives for participating in learning activities are called learning motives, that is, internal motives that promote student learning activities. Learning motivation is generally considered to have two basic factors: internal drive and incentive. "Inner driving force refers to an internal driving force generated on the basis of the needs of the organism and is an internal stimulus". "Inducements are external stimuli or situations that can cause individual motivation and are targets that the organism tends or evades".

The theory is guided by behavioural psychology, emphasizing that the learning process is a process of "stimulus-response-intensification". It is advocated that the learners should be constantly stimulated, and the appropriate positive reinforcement and negative reinforcement should be made based on the learners' responses so that the learners' behaviour can achieve the desired goal. Representatives include Thorndike, Pavlov, and Skinner. This theory also provides a certain theoretical basis for multimedia teaching design. According to this 
learning theory, Gagne and Briggs proposed several instructional design principles that have important influence on the design of CAI software. The main principles are Contiguity, Repetition, and Feedback and Reinforcement. These principles guide the production of many multimedia courseware, such as back-to-word courseware, learning typing courseware, and arithmetic operations and practice courseware.

\subsection{The Theory of Constructing a Personalized Learning Environment in Foreign Languages}

The theory of foreign language learning, that is, the second language learning theory is a branch of learning theory, it still follows the general learning theory, but it also has unique characteristics of the discipline. The mechanism of language acquisition and learning is a more complex issue involving different perspectives such as linguistics, psychology, sociology, and anthropology. Foreign language learning has different learning motives and psychological characteristics from the Department of Mathematical Chemistry. It needs not only the stimulation of the external language environment, but also the learners' independent construction of language meaning [3]. Practice has proven that learning a language in a second language environment is more conducive to the learner's participation in the dialogue, but what the external stimuli require is not a simple response from learners, but active thinking, experience, and construction. In order to train learners to eventually translate language learning into real communication, foreign language learning needs to adopt different learning strategies and methods than traditional memory, recitation, and mechanical reinforcement.

For linguistic subjects, if we continue to take care of foreign language learning from the perspective of behaviourist learning theory, cognitivism learning theory, and constructivism and contextual cognitive theory developed from cognitive psychology, this paper tends to use constructivism and situational recognition as we can see from Figure 2. To understand the theory of foreign language learning from the perspective of theoretical knowledge, this is not only to maintain theoretical consistency with the learning environment and the individualized learning that will be discussed below, but also because of the rationality of constructivism and contextual cognitive theory in supporting individualized learning in the classroom.

With the flourishing development of applied linguistics, under the influence of cognitive psychology and functionalist linguistics, the practice of foreign language teaching and learning has gradually shifted from focusing on forms to meaning and function, emphasizing the cultivation of communicative competence and pragmatic competence. Therefore, some theories and hypotheses about language learning are worth learning from, such as: Chomsky's language acquisition mechanism, monitoring model, and sentiment filtering theory. These theories shed light on the nature and structure of language as well as the forms and results of language transformation in the learning process. 


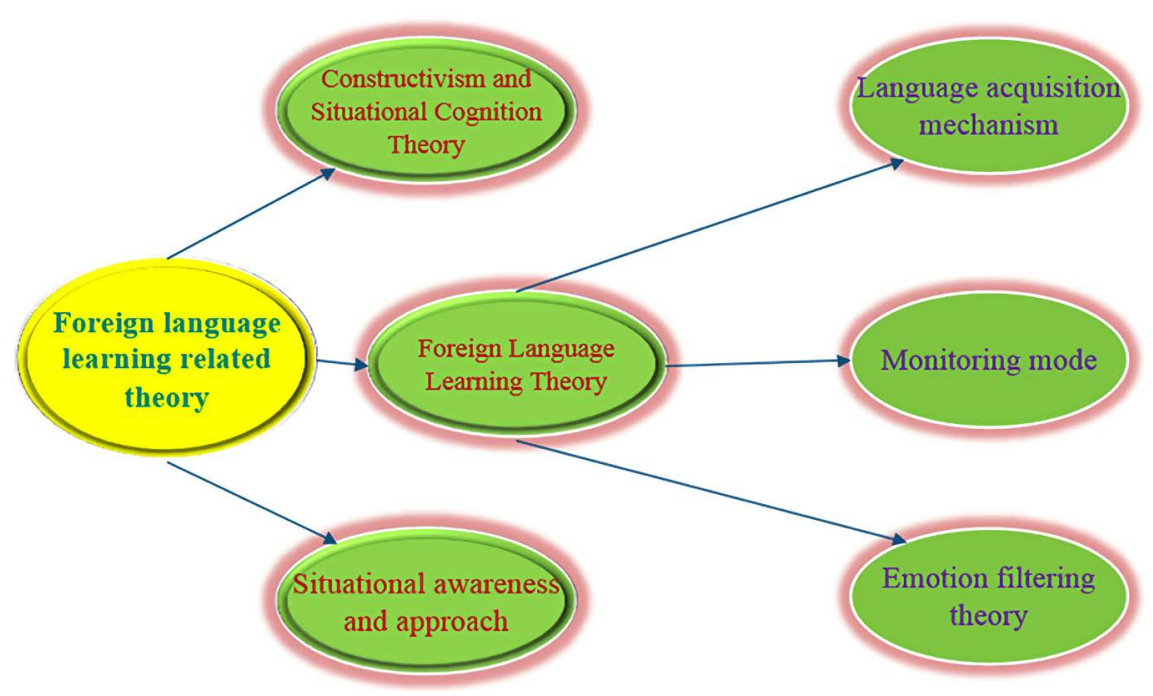

Figure 2. Personalized foreign language learning related theory [4].

With the support of learning theory, as a language subject, foreign language learning also needs learning strategies and methods that are consistent with the features of language learning mechanisms. The situational teaching, which is consistent with the learning task situation in the basic theory of learning environment, is the best choice for constructing foreign language personalized learning in the classroom. The theoretical basis of situational teaching comes from cognitive psychology and sociolinguistics [5]. Constructivism in cognitive psychology believes that learning comes from experience. This kind of experience must be practiced in certain real situations to gain true knowledge. Sociolinguistics emphasizes the topic and occasion of language. As mentioned earlier, contextual cognitive theory is the development of constructivist learning theory. We can see from the clues of behaviourism, cognitivism, constructivism, and situational cognitivism generated on this basis: situational cognition theory, which integrates cognitivism and constructivism, reintegrates into more social and humanistic Factors have evolved into the current situational cognitive theory and situational approach. Under the concept of situation, teaching practice requires that real learning tasks match the conditions of reality, and puts forward higher requirements for creating a rich teaching environment so as to provide more and wider for discovery, exploration, design, practice, and construction.

\section{The Optimization of Foreign Language Personalized Learning Environment in Classroom}

\subsection{The Definition of Foreign Language Personalized Learning Environment in the Classroom}

The learning environment is the place where the learning activities take place. As an external factor, places mainly include classrooms, campuses, families, and other social sites. This is a learning environment based on the principle of 
teaching and behaviorism. It aims to promote the learning of learners through external hardware facilities or equipment. The learning environment is the support of various learning resources for learning activities. This is still the recognition of the learning environment from external factors. It includes knowledge resources, tool resources, human resources, and of course places where the learning activities take place. However, it emphasizes the use of these resources to assist in the occurrence or persistence of learning activities. Obviously, the resource concept goes one step further than the concept of a place because it places learners and learning activities at the center. The learning environment is a learning task or a learning situation. Task scenarios that differ from sites and resources include not only places, resources, but also learning requirements for the purpose of achieving learning tasks. The three aspects of comprehensive sites, resources, and tasks are called learning situations. In this regard, support can be found in contextual cognitive theory. Situational cognitive theory holds that learning and thinking are context-based. They cannot be isolated in the individual's brain but in the human brain through cultural activities or tools in the context. Those interact with activities, tools, and cultures. Split learning and knowledge are inert. Knowledge must be presented in real situations to stimulate learners' real cognitive needs. This is because knowledge exists in specific activities, situations, and cultures. People can learn so-called knowledge only when they enter it.

There are many discussions about the learning environment in the network. The acquisition of resources and the setting and completion of tasks are the key to the current network environment. However, in the classroom, it seems that the teachers' arrangement and the information from the textbooks are what we face. This is the wrong traditional teaching perspective. In the classroom, the learning environment can still be constructed through certain learning situations. Of course, the learning situation cannot replace the learning environment, because the learning environment is a more macro concept, and the learning situation is aimed at different learning objectives and learners have more targeted and personalized learning environment. In the text, a new analysis of the learning environment is based on the characteristics of classroom learning activities. It includes the external environment and internal environment. The external environment includes learning resources, learning tasks, etc.; the internal environment includes learner characteristics, learners' performance levels, etc. The structure and relationship are shown in Figure 3.

\subsection{The Optimization of Foreign Language Personalized Learning Environment}

Personalized learning is a new way of learning that emerged from the rise of online learning under the guidance of constructivism. If we still hold a preconceived mindset and believe that personalized learning is a form of autonomous learning in a network environment, it is obviously too rigid. Personalized learning, like autonomous learning and collaborative learning, is a flexible learning 


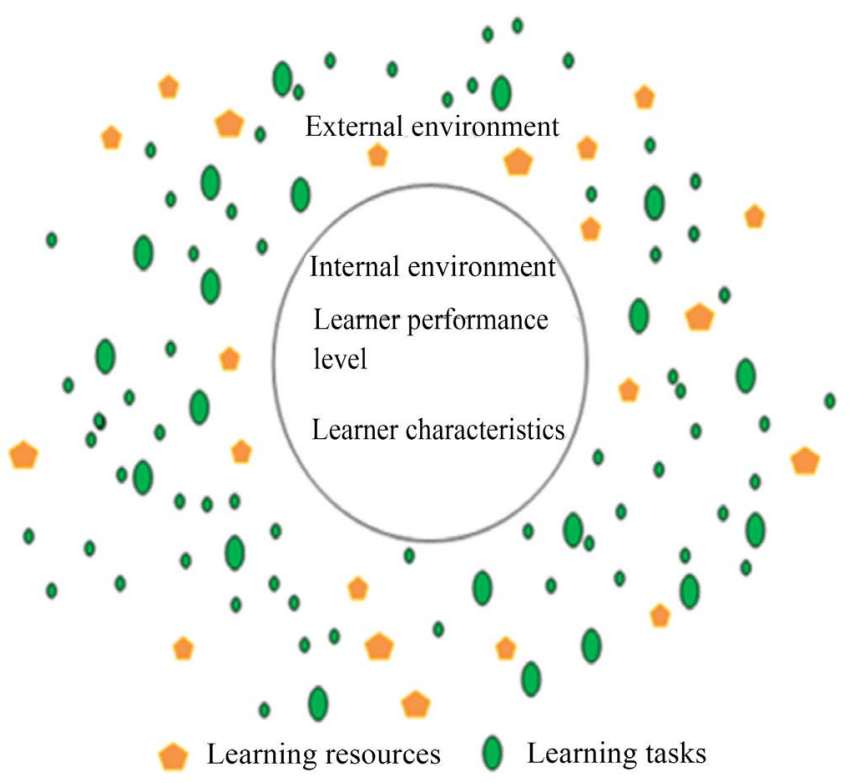

Figure 3. Personalized learning environment map [6].

concept that can be applied to any environment. It can be applied to all environments, including schools, classrooms, and families, as long as it has the elements that motivate learning activities. The foreign language personalized learning environment should be a task context that satisfies most of the class's learners' learning goals, learning characteristics, and makes their learning activities continue to be effective. This situation should not only meet the individual needs but also promote the learning of most students; it should also include tasks, resources, activities, tools, and all other abstract and materialized conditions that make learning activities happen. The foreign language personalized learning environment in the classroom has the dual characteristics of classroom and subject:

Classroom definition of a personalized learning environment. Classroom is a relatively small environment where space and time are defined and known relative to the network environment. Most of the learners' activities need to be conducted in a timely manner in the classroom with the help and supervision of the teacher. Compared with personalized learning in the Internet environment, personalized learning in the classroom has its own advantages, but there are also deficiencies. The advantages are: First of all, the learning activities have been implemented. Learning activities in the classroom can generally be completed within a specified period of time. This helps the completion of the learning plan. It also contributes to the control of unrelated variables in the experiment and measurement and feedback of the activity results. On the other hand, the classroom environment is a relatively more physics-based environment, learning peers, mentors, and learning tools are more concrete and realistic for learners. This helps the construction of context and motivates the enthusiasm of learners. The third aspect is learning activities in the classroom. There are better adjust- 
ments and supplements to the learner's psychological factors, which can enhance the learners' awareness of competition, collaboration, and support. The inadequacies are: in the network environment, different personalized tasks can be generated through powerful computing functions and independent terminal devices [7]. In the classroom, it is difficult to achieve the task completely personalized by relying solely on the individual ability of the teacher. Based only on the individual characteristics of the learners, they can be reduced as much as possible, grouped homogenously, and maintain the relative stability of this grouping, but without losing flexibility. Therefore, in this experiment, establishing a learner model becomes the key.

Disciplinary features of personalized learning environment. The learning of the second language has its unique psychological and learning theory. According to Gardner's multi-intelligence and Gagne's classification of learning results, second language learning and mathematics, arts and other knowledge acquisition have different psychological functions and learning conditions. First of all is the impact of mother tongue on personalized learning. Learning in the classroom is generally conducted in the context of the mother tongue, and the educators generally do not consider the influence of the second language. For the learning of the second language, the influence of the mother tongue on learning is a very crucial factor. Learning in the second language can generally be divided into two types: learning the language in the second language environment and learning the second language in the first language environment [8].

\section{Case Study of Personalized Multimedia Customization System}

\subsection{MM4U Framework}

German researcher Susanne put forward MM4U (Multimedia for you), a software framework for personalized multimedia content generation. This framework is based on user feature information for multimedia generation. It takes media data, related metadata and user information as input information processed by the system; after the user issues a request, the personalization engine searches the user's information and metadata, and selects the most suitable media information. At present, this framework can only be applied on the Internet [4]. This article attempts to draw on this idea and use materialization and human means to enable it to be realized in classroom learning.

Connection: As the bottom layer of the framework, it is a connection port for user files and media data, and mainly accepts requests from the user and data of the media. (When there are many different systems and formats, the user file connection is selected from existing channels and retrieved to match the user).

Entrance: It is on the upper layer of the connection, including user information and media information entrance. This layer will initially process the information and media that will be applied next and provide it to the multimedia component. Connections and portals are designed primarily to avoid duplica- 
tion of user model and multimedia content management, while providing a seamless integration of interfaces and complex data models.

Multimedia components: This layer will use SMIL (Synchronized Multimedia Integration Language), Madedo and ZYX and other simultaneous multimedia integrated languages handle user information and multimedia information. At this level, multimedia component plug-in applications will also be implemented.

Demonstration generator: The components mentioned in the previous layer are the internal presentation of multimedia content, and the fourth layer of the presentation generator is a component that transforms the internal presentation into a presentation model.

Multimedia presentation: The multimedia presentation component at the highest level will identify the application interface and present the multimedia content. With this component, the user can identify his own demonstration model, which is essentially the final externalization of the internal demonstration. On the other hand, users can also integrate demo components in existing common multimedia presentation formats.

\subsection{Application Case Analysis in Foreign Language Learning}

The system (teachers or learners who help classroom learning) uses the learner's personal document data as basic information for multimedia generation, which includes a learner's learning task (learning to use everyday shopping terms in English) and personal information [9]. Folders (learning age, home and school environment, history and current level of learning English, etc.), the information can be saved and updated by the system each time. Multimedia environment requirements (for example, this learning environment requires tasks integration of multimedia elements such as characters, languages, videos, etc.), the information is entered into the system via a connector.

1) At the entrance (Accessor), personal information and multimedia information are processed, classified and archived. Here, the requirements of the virtual shopping environment are refined to classify characters, audio, video, and pictures; the learner's personal information is also processed appropriately so that the next time the system is used, the work is repeated, and new information and tasks are retained.

2) After the portal is processed, a task and multimedia element suitable for the learner are generated. Assume that the task here is to purchase magazines in bookstores. The multimedia elements involved include a bookstore shopping guide (English as its mother tongue), pictures of various magazines, and so on.

3) After the above processing, in the multimedia component (multimedia composition) layer, the book acquisition tasks and the required multimedia environment, in the system through SMIL and other tools to generate an overall component, that is, the task and multimedia content preliminary integration into the whole. 
4) The presentation format generator transforms the components of the book acquisition task and multimedia content into a model, just like the self-service travel model in the MM4U case.

5) Finally, through multimedia presentations (multimedia presentations), like the game interface or traditional multimedia presentations, displayed in front of learners, the difference is that the display of the book environment, not only for this customized individual, it also can accept the insertion of new tasks and multimedia content.

Learning from this process, you can formulate a general idea for the construction of a foreign language-specific learning environment in the classroom: The first step is the formation of a learner model. Next teachers use informative methods (e-forms or databases) to create learner information files that store basic learner information. Then based on the first two steps, provides cognitive tools for learners to complete learning activities. Cognitive tools are also multimedia models [10]. The fourth step is to integrate the above three models to form a personalized learning environment. The personalized customization system in the case is an intelligent process that utilizes technical support. The following figure shows the three basic models that form a personalized learning environment and the relationships between them in the classroom as can be seen from Figure 4 .

\section{Conclusions}

The architectural personality of learners who are brave in learning a foreign language is the fundamental basis for constructing a personalized learning environment. The personality characteristics of learners include classroom, family, and social at the macro level; and micro-levels include learning orientation, learning style, and learning performance. Starting from the two levels of observation and questionnaire survey, we can grasp the learner's personality characteristics

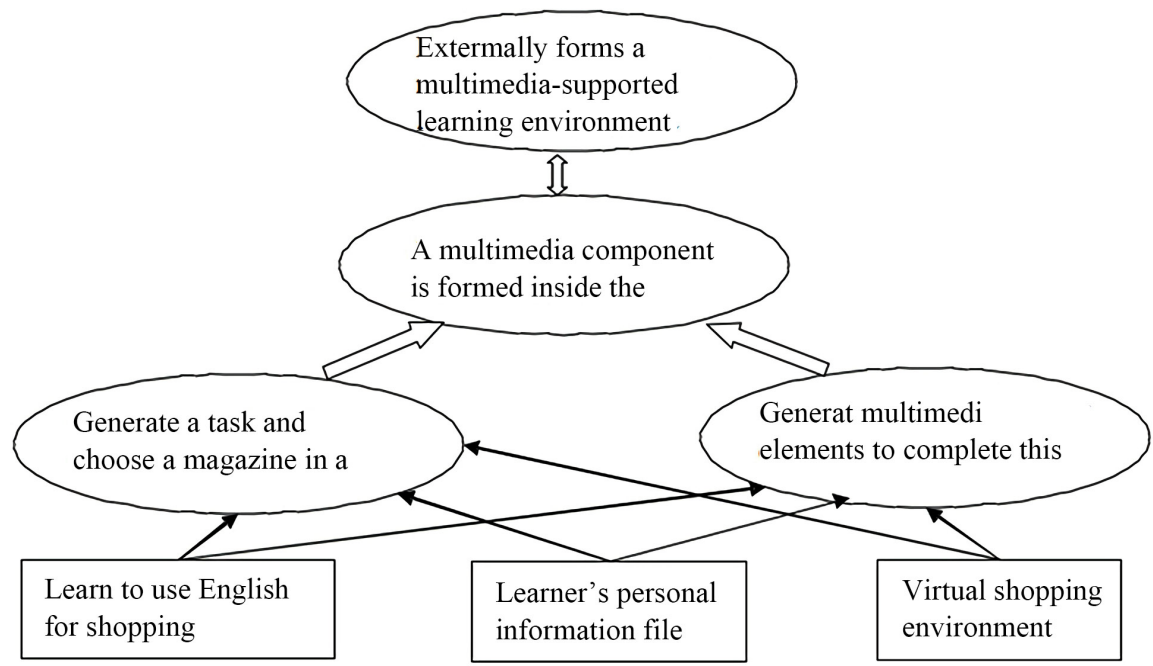

Figure 4. A diagram of the courage to learn a foreign language [7]. 
more comprehensively. The creation and updating of the learner's personal information database can help teachers change the existing learning environment in a timely manner and provide learners with a foreign language-individual learning environment, which will help them to improve their academic performance. In the process of construction, the establishment of the learner information database has successfully applied the concepts of cognitive distribution and dynamic update to the classroom teaching environment.

As mentioned above, the construction of personalized learning environment is important, but individual learning is a dynamic process. How to better and more accurately according to the dynamic changes of individual learning and cognitive level timely adjust and update the teaching management mode, to achieve multiple total body, harmonious balance needs more wisdom in classroom factors intervention, which is the next step to be focused and fully considered.

\section{Conflicts of Interest}

The author declares no conflicts of interest regarding the publication of this paper.

\section{References}

[1] Hao, X. (2013) Analysis of Teaching Achievement Indicators in English Education Based on Multimedia Technology and Competency Model. Journal of Convergence Information Technology, 32, 902-911.

[2] Guan, X., Wang, D. and Zhang, R. (2012) A Study on Experiential Translation Teaching under Multimedia Network Environment. Theory and Practice in Language Studies, 2, No. 9. https://doi.org/10.4304/tpls.2.9.1835-1840

[3] Chen, B.W. (2014) Embedded Multimedia Technology Based on Matrix Eigenvalue Extraction Algorithm. Applied Mechanics \& Materials, 608-609, 585-588. https://doi.org/10.4028/www.scientific.net/AMM.608-609.585

[4] Park, J., Kim, M. and Rho, S. (2015) A Study for Personalized Multimedia Information Services. The Journal of Society for e-Business Studies, 20, 79-87. https://doi.org/10.7838/jsebs.2015.20.3.079

[5] Zhang, X. (2014) Research on the Gray Hierarchy Evaluation Model Based on Multimedia System and English Teaching Evaluation. International Journal of Multimedia \& Ubiquitous Engineering, 9, 181-192. https://doi.org/10.14257/ijmue.2014.9.8.16

[6] Chica, S.D.L., Ahmad, F., Gu, Q., et al. (2009) A Personalized Learning Environment. Joint International Conference on Digital Libraries. ACM.

[7] Hwang, W.Y., Huang, Y.M., Shadiev, R., Wu, S.Y. and Chen, S.L. (2014) Effects of Using Mobile Devices on English Listening Diversity and Speaking for EFL Elementary Students. Australasian Journal of Educational Technology, 30, 503-516. https://doi.org/10.14742/ajet.237

[8] Zarri, G.P. (2014) Conceptual and Content-Based Annotation of (Multimedia) Documents. Multimedia Tools \& Applications, 72, 2359-2391.

https://doi.org/10.1007/s11042-013-1463-3

[9] Ou, X. and Hao, W. (2017) Analysis of Physical Education Teaching Model Based 
on Multimedia Information Technology. Boletin Tecnicol Technical Bulletin, 55, 66-71.

[10] Cao, A. (2017) Research on the Interactive Classroom of English Situational Teaching Based on Multimedia Network. Boletin Tecnico/ Technical Bulletin, 55, 132-138. 